\title{
Bergson y la crítica al esquematismo de la representación: la filosofía como máquina de plantear problemas y horizonte del pensar
}

\author{
José Ezcurdia
}

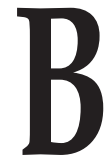

ergson establece una crítica al conocimiento racional que se funda en la determinación de la incapacidad de éste para dar cuenta de la duración, es decir, de un plano metafísico que es no en tanto que está hecho, sino en tanto que se hace. Para Bergson el conocimiento intuitivo revela de manera inmediata a la conciencia del sujeto el dato de una realidad que es duración, unidad dinámica, flujo creativo, y, sin embargo, constata que la razón misma, en sus diversas presentaciones y desde las diversas escuelas a las que da lugar, pretende dar cuenta de ésta con una serie de nociones abstractas y esquemáticas, que no pueden señalar su forma original. Para Bergson el concepto racional no alcanza a asir una duración siempre singular que no puede ver representada su naturaleza intensiva, sin ver negada su forma en tanto proceso.

Según nuestro autor, la función racional proyecta sobre la categoría del espacio la forma de una realidad que dura, reduciéndola a una serie de conceptos y símbolos sujetos a una serie de leyes lógicas y causales, por las cuales no se puede dar cuenta del carácter continuo y la novedad permanente en la que se constituye como tal.

Bergson hace expresos estos planteamientos al mostrar los soportes epistemológicos que hacen posible la paradoja zenoniana de Aquiles y la tortuga.

Aquiles pretende rebasar a la tortuga y sin embargo no lo logra, pues cada vez que éste la alcanza, aquella se ha adelantado un paso. ¿Cuál es el secreto de esta paradoja utilizada como argumento por el eleata para probar la tesis de la esencial inmovilidad de lo real?

Aquiles no rebasa a la tortuga porque su movimiento ha sido fraccionado arbitrariamente al ser proyectado sobre el fondo del espacio, negándose así su forma peculiar. Entonces se presenta una reconstrucción del movimiento de Aquiles, con fundamento en una serie de inmovilidades que tienen como regla precisamente el paso también fraccionado de la tortuga: una tortuga 
llamada Aquiles persigue a otra, y jamás la rebasará, pues tiene un paso como el suyo, pero va detrás de ella.

La movilidad característica e indivisible que presenta la carrera de Aquiles, la aceleración producto de su brío y su empuje, se sustituye por un movimiento indefinidamente divisible sujeto a un plan preestablecido, que no refleja su duración constitutiva.

De esta confusión entre el movimiento y el espacio recorrido por el móvil han nacido, a nuestro parecer, los sofismas de la escuela de Elea: porque el intervalo que separa dos puntos es divisible infinitamente, y si el movimiento estuviese compuesto de partes como las del intervalo mismo, jamás sería salvado el intervalo. Pero la verdad es que cada uno de los pasos de Aquiles es un acto simple, indivisible, y que después de un número dado de estos actos, Aquiles habrá sobrepasado a la tortuga. La ilusión de los eleatas proviene de identificar esta serie de actos indivisibles y sui generis con el espacio homogéneo que los sostiene. Como este espacio puede ser dividido y rehecho según una ley cualquiera, se creen autorizados a reconstruir el movimiento total de Aquiles, pero no ya con pasos de Aquiles, sino con pasos de tortuga: sustituyen en realidad a Aquiles persiguiendo a la tortuga por dos tortugas reguladas la una sobre la otra, dos tortugas que se condenan a hacer el mismo género de pasos o de actos simultáneos, pero de manera que no se alcancen jamás. ${ }^{1}$

Es vana pretensión reconstruir el movimiento continuo de Aquiles con pesados pasos de tortuga que, como golpes de martillo, resultan inmovilidades respecto al ligero y veloz trote de aquél. Lo móvil no puede ser reconstruido a partir de la yuxtaposición de lo inmóvil, lo discreto no puede reconstruir lo continuo, ni ningún símbolo puede dar cuenta de un progreso continuo.

Aquiles no alcanza a la tortuga porque su movimiento, en tanto acto simple e indivisible, ha sido despojado de su forma positiva por un espacio que posibilita subdivisiones arbitrarias, las cuales producen tan sólo su burda imitación. Aquiles no puede rebasar a la tortuga ya que se confunde al tiempo o duración con el espacio, a Aquiles que se desplaza en un movimiento sostenido con el paso fraccionado de una tortuga que muestra una forma radicalmente diferente a la de aquél.

${ }^{1}$ En este artículo utilizaremos la edición canónica de las obras completas de Bergson para la conmemoración del centenario de su nacimiento: Henri Bergson, Oeuvres. París, PUF, 1991. H. Bergson, "Ensayo sobre los datos inmediatos de la conciencia", en Oeuvres, p. 75. 
Para Bergson la razón lleva a cabo un juego de desplazamientos y sustituciones de orden simbólico fundados en la categoría del espacio homogéneo, que tiene como consecuencia la negación del dato inmediato de una duración (la carrera de Aquiles), que no puede ser reconstruida con una serie de esquemas y conceptos preconcebidos (el paso de la tortuga).

La razón no puede dar cuenta de la duración puesto que entre el espacio del que se vale la propia razón para dar cuenta de lo real y la duración misma, no hay una diferencia de grado, sino de naturaleza. Espacio y duración, son para Bergson formas irreductibles entre sí. Con el fin de precisar y subrayar estos planteamientos, conviene recurrir a un análisis de las figuras de las multiplicidades cuantitativas y de las multiplicidades cualitativas.

Las nociones de multiplicidad cuantitativa y multiplicidad cualitativa contribuyen a iluminar tanto la naturaleza de una realidad, que es duración y progreso dinámico, como también una espacialidad a partir de la cual se niega su forma efectiva. Las nociones de multiplicidad cuantitativa y multiplicidad cualitativa brindan el instrumental conceptual que resulta adecuado para reflejar el ocultamiento que opera la razón de una realidad que se despliega desbordando los esquemas de la propia razón.

Una multiplicidad cuantitativa es aquella que es indefinidamente divisible. Esta divisibilidad va de la mano de la impenetrabilidad y de la homogeneidad de las partes que la constituyen. Divisibilidad, impenetrabilidad y homogeneidad son factibles porque toda multiplicidad cuantitativa aparece como una representación que se hace posible en el fondo del espacio. El espacio es el principio de la determinación de toda multiplicidad cuantitativa, en la medida que presenta el horizonte sobre el que se adosan y se subdividen de manera indefinida ilimitadas unidades homogéneas y exteriores entre sí.

En este sentido, señala Bergson, las multiplicidades cuantitativas implican la representación de ilimitadas unidades homogéneas e impenetrables que por su adición constituyen una cantidad que se expresa en un número determinado. Cualquier número refleja una cantidad que se concibe por la determinación y la yuxtaposición de ciertos elementos divisibles e impenetrables que carecen de toda cualidad o carácter peculiar.

La posibilidad del número y de toda adición está dada no sólo por la homogeneización, la divisibilidad y el carácter exterior de ciertos elementos, sino también y fundamentalmente, por la categoría del espacio. Es porque las cantidades suponen al espacio que resultan divisibles y con una exterioridad entre sus componentes homogéneos, de modo que se ordenan precisamente en una yuxtaposición determinada de partes que se expresa en un número. El número es un símbolo que da cuenta de la cantidad de una forma cualquiera que ha sido refractada en el fondo del espacio para ser determinada como multiplicidad cuantitativa. 
Supongamos todos los corderos del rebaño idénticos entre sí; difieren al menos por el lugar que ocupan en el espacio; de no ser así, no formarían un rebaño. Pero dejemos de lado los cincuenta corderos para no retener más que su idea. O los comprendemos todos en la misma imagen, y es necesario por consiguiente que los yuxtapongamos en un espacio ideal; o repetimos cincuenta veces consecutivamente la imagen de uno solo de entre ellos y parece entonces que la serie ocupa un lugar en la duración antes que en el espacio. Pues si yo me figuro alternativa y aisladamente cada uno de los corderos del rebaño, jamás me las habré más que con un solo cordero. Para que el número vaya creciendo a medida que avanzo, es preciso que retenga las imágenes sucesivas y que las yuxtaponga a cada una de las nuevas unidades cuya idea yo evoco: ahora bien, es en el espacio donde se opera una parecida yuxtaposición y no en la duración pura. ${ }^{2}$

Toda multiplicidad cuantitativa revela no un despliegue de momentos heterogéneos e interiores entre sí que generan un movimiento simple y continuo, sino un adosamiento de unidades homogéneas e impenetrables que se traduce en una serie de repeticiones. Estas repeticiones constituyen una cantidad y encuentran su simbolización precisamente en un número.

Multiplicidad cuantitativa, cantidad y número son posibles gracias a la categoría del espacio que descompone toda forma en una pila de unidades homogéneas, divisibles y exteriores entre sí.

Una multiplicidad cualitativa, por el contrario, es indivisible ya que es continua. Sus partes no implican exterioridad y homogeneidad, sino mutua penetración y heterogeneidad. Ésta se despliega en el tiempo o duración, porque sólo en éste podría desarrollarse pues se determina como intensidad.

Las multiplicidades cualitativas presentan un movimiento ininterrumpido en el que cada elemento se encuentra penetrado por la totalidad que le precede, de modo que su presencia genera un progreso, y no un aumento que se determinara como yuxtaposición. Este progreso, en tanto preñado justamente de una multiplicidad de carácter heterogéneo, hace del despliegue de la intensidad misma la expresión de una cualidad, ya que la interacción inmediata y la penetración de lo heterogéneo da lugar a una forma simple y peculiar, que no podría ser proyectada en el fondo del espacio para ser dividida y verse explicada justo con base en términos cuantitativos.

La relación interna, dinámica e inmediata de una multiplicidad heterogénea se traduce en el progreso móvil de una cualidad que no es susceptible de ser

${ }^{2}$ Ibid., p. 52. 
reducida a ningún símbolo, que reflejara una cantidad compuesta de partes homogéneas.

El vínculo inmediato y la mutua penetración entre las partes de una unidad preñada de una multiplicidad heterogénea son el principio de la cualidad, tal como lo muestra una melodía que delata su errónea ejecución más por la modificación del tono expresivo y del progreso continuo en el que se despliega, que por un error verificable en la lectura de su partitura.

La prueba de ello es que si rompemos la medida insistiendo más de lo razonable sobre una nota de la melodía, no es su prolongación exagerada, como tal duración, la que nos advertirá la falta, sino el cambio cualitativo aportado por ella al conjunto de la frase musical. Se puede pues concebir la sucesión sin la distinción, y como una penetración mutua, una solidaridad, una organización íntima de elementos, cada uno de los cuales, representativo del todo, no se distingue y aísla de él más que por un pensamiento capaz de abstraer. Tal es sin duda alguna la representación que se haría de la duración un ser a la vez idéntico y cambiante, que no tuviese ninguna idea del espacio. ${ }^{3}$

Toda multiplicidad heterogénea con penetración recíproca entre sus elementos, al determinarse como el movimiento continuo de una intensidad, ve en su desarrollo la expresión de una cualidad. La interpenetrabilidad y la heterogeneidad de los momentos de una multiplicidad que se determina como unidad dinámica, hace que cada momento de esta multiplicidad contenga a los que le preceden, y presente sin embargo un matiz propio y peculiar que hace posible el desarrollo mismo de la propia multiplicidad, precisamente en términos de un despliegue cualitativo.

El tiempo o duración es despliegue de multiplicidades cualitativas que, en tanto intensidades, no tienen al espacio como fondo de una representación y una simbolización que hagan posible la determinación de su forma como cantidad. Toda multiplicidad cualitativa refleja un movimiento continuo dotado de diversos momentos heterogéneos que no podría ser plasmado en el fondo del espacio sin ser negado en cuanto a la forma peculiar en la que se constituye como tal.

Para acentuar y matizar la diferencia entre las multiplicidades cuantitativas y las multiplicidades cualitativas, y con ella delinear con mayor precisión la diferencia entre el conocimiento racional y la forma de la duración, Bergson ofrece el ejemplo de una misma serie de campanadas que es aprehendida desde dos ópticas diferentes, una cualitativa y otra justamente cuantitativa.

${ }^{3}$ Ibid., p. 68. 
Desde la aprehensión de dicha serie fundada en una óptica cualitativa, se aprecia cómo las campanadas de la misma se subsumen unas en otras, fundiéndose entre sí a medida que la propia tanda que constituyen se despliega, generando así una unidad móvil y dinámica que crea un timbre, un ambiente y un color único que se actualiza y se transforma al paso de su propio desenvolvimiento.

Desde la óptica cuantitativa, se muestra cómo el paso de las campanadas no es más que una retahíla de puntos que se fijan sobre el espacio o, más bien, sobre el tiempo espacializado, a la manera de un metrónomo que establece una serie regulada de golpes, según la métrica de un determinado compás.

En la primera serie, la multiplicidad de las campanadas genera cualidad y formas novedosas. En la segunda, esta multiplicidad es negada en tanto cualidad y aparece tan sólo como una suma de partes impenetrables que produce una pura repetición de una misma forma homogénea.

Ciertamente, los sonidos de la campana me llegan sucesivamente, pero de dos cosas, una. O retengo cada una de estas sensaciones sucesivas para organizarlas con las otras y formar un grupo que me recuerda un aire o un ritmo conocido: entonces no cuento los sonidos, me limito a recoger la impresión, por decirlo así, cualitativa [...] bien me propongo explícitamente contarlos, y será preciso entonces que los disocie, y que esta disociación se opere en algún medio homogéneo en el que los sonidos, despojados de sus cualidades, vaciados de alguna manera, dejen huellas idénticas de su paso. ${ }^{4}$

La diferente apreciación del ritmo en una serie de campanadas ilustra la distinción entre las multiplicidades cualitativas y las multiplicidades cuantitativas, y con ella también, la distinción entre la forma de una representación articulada en la categoría del espacio y la forma de la duración que se constituye en su propio despliegue inmanente.

Cuando las campanadas se ven determinadas como una multiplicidad cualitativa, manifiestan la forma de un flujo que se articula como un oleaje en el que se funden diversos estados, generando una atmósfera propia con una coloración y una tintura singular, que no puede ser expresada por ningún concepto ni por ningún símbolo. Cuando esta serie de campanadas se articula en una multiplicidad cuantitativa, implica una reducción de toda intensidad a la mera representación de una monótona repetición carente de todo contenido peculiar, que es resultado de la espacialización de su duración constitutiva.

${ }^{4}$ Ibid., p. 59. 
En la tanda de campanadas articulada en la multiplicidad cualitativa aparece una duración que se manifiesta en un presente creativo, pues absorbe en su desenvolvimiento el pasado inmediato que le precede, para lanzarlo a un futuro novedoso en el que afirma su propia forma intensiva. La penetrabilidad móvil de los elementos que constituyen la multiplicidad cualitativa implica la determinación de ésta como un progreso creativo que se actualiza en un desenvolvimiento que genera formas inéditas.

En la multiplicidad cualitativa, pasado y futuro inmediatos se funden en un presente que dura creando, por la heterogeneidad y la interpenetración misma de sus componentes, el despliegue de una cualidad. "Una sensación, sólo por el hecho de prolongarse, se modifica hasta el punto de hacerse insoportable. Lo mismo no permanece aquí lo mismo, sino que se refuerza y se agranda con todo su pasado". 5

Toda multiplicidad cualitativa muestra una penetración dinámica de los elementos en los que se despliega, pues su forma se articula por la apropiación de un pasado inmediato que la nutre y la modifica, y le otorga un carácter creativo. La multiplicidad cualitativa, al desenvolverse como duración, presenta una inmanencia por la que los elementos que la constituyen recaen constantemente sobre ella misma, promoviendo su continua transformación y la determinación de su forma como una intensidad siempre nueva.

En cuanto a la serie de campanadas que aparece como multiplicidad cuantitativa, Bergson apunta que en ella se establece un tiempo espacializado en el cual el pasado, el presente y el futuro no guardan una relación inmanente y creativa, sino otra que da lugar a múltiples detenciones o inmovilidades que, al adosarse, generan una serie de simultaneidades de las que no se puede desprender ninguna forma inédita. El tiempo espacializado hace que cada campanada no sea anterior a las demás y no aparezca como la prolongación de un despliegue creativo. Por el contrario, en esta serie cada campanada resulta una entre múltiples repeticiones que por su adición señalan justamente una simultaneidad que implica una cantidad, un número o en última instancia, un símbolo o esquema determinado. El tiempo no opera sobre las multiplicidades cualitativas, pues no produce progreso alguno ni crea nada radicalmente nuevo.

Cuando yo sigo con los ojos, sobre la esfera del reloj, el movimiento de la aguja que corresponde a las oscilaciones del péndulo, no mido la duración, como parece creerse; me limito a contar simultaneidades, que es muy diferente. Fuera de mí, en el espacio, no hay nunca más

${ }^{5}$ Ibid., p. 102. 
que una posición única de la aguja y del péndulo, porque de las posiciones pasadas ya nada queda. ${ }^{6}$

En las multiplicidades cuantitativas el presente no absorbe su pasado, sino que guarda una relación externa con él, de modo que el presente mismo no se ve enriquecido por la influencia de éste, y no puede por ello generar ningún movimiento que se exprese en la creación de alguna cualidad concreta, sino sólo asegurar la reedición de una misma forma homogénea.

La duración se ve negada en el momento en el que se le proyecta en el fondo del espacio, determinándosele tan sólo como múltiples inmovilidades yuxtapuestas o simultaneidades que se resuelven como una representación meramente repetitiva.

Entre el movimiento espacializado y la duración, entre la representación del movimiento y el movimiento mismo, hay una completa desproporción que es imposible salvar, ya que los primeros términos de cada pareja, en tanto señalan detenciones exteriores y yuxtapuestas, se refieren a cosas u objetos, mientras que los segundos, al referirse a intensidades creativas, expresan más bien progresos.

Como decíamos al inicio de este texto, la duración es lo que se hace, el espacio se refiere a lo que es. La duración muestra el despliegue de la cualidad como progreso. El espacio representa sólo una sucesión de elementos inmóviles que sólo pueden dar cuenta de las proporciones de una cosa hecha.

La duración es progreso y, por ello, no puede ser dividida sin ver anulada a su vez la cualidad peculiar en la que se manifiesta, la cual es producto precisamente de la interpenetración móvil de sus elementos constitutivos. Las cosas, por su parte, pueden ser divididas de manera ilimitada y no sufrir transformación alguna de su naturaleza justo en tanto cosas.

La duración no puede ser reconstruida con base en una división suya que se tradujera en un aumento o una reducción de ciertos elementos impenetrables, pues estas divisiones equivaldrían a la negación de su forma como unidad dinámica y progreso, y por ello también a la negación de su naturaleza como intensidad creativa y despliegue cualitativo.

Ciertamente, la conciencia pura no percibe el tiempo bajo forma de una suma de unidades de duración; abandonada a sí misma, no tiene ningún medio, ninguna razón incluso para medir el tiempo, pero un sentimiento que durase un número de días dos veces menor, por ejemplo, no sería ya para ella el mismo sentimiento: faltarían a este estado de conciencia una multitud de elementos que han venido a enriquecer

${ }^{6}$ Ibid., p. 72 . 
y a modificar su naturaleza. Es verdad que, cuando damos a este sentimiento un cierto nombre, cuando lo tratamos como a una cosa, creemos poder disminuir su duración en la mitad, por ejemplo, y también en la mitad de la duración de todo el resto de nuestra historia; esto, parece, sería siempre la misma existencia a escala reducida. Mas olvidamos entonces que los estados de conciencia son progresos y no cosas, y que si los designamos a cada uno por una sola palabra es para mayor facilidad del lenguaje; que viven y que, por eso mismo, cambian sin cesar; que, por consiguiente, no se sabría restarles momento alguno sin privarles de alguna impresión para modificar así la cualidad. ${ }^{7}$

Los progresos son en tanto se hacen. Los objetos son en la medida que están hechos. Los progresos y los objetos muestran una diferencia de naturaleza y no de grado, pues mientras los primeros se articulan en la duración, los segundos se fundan en el espacio o en un tiempo espacializado que jamás podría identificarse con la duración misma, pues sólo da lugar a simultaneidades con una exterioridad entre sus partes y no a unidades heterogéneas, dinámicas y creativas que se actualizan en un movimiento simple. Los objetos al presentar al espacio como fondo, pueden ser divididos ilimitadamente sin dejar de ser justamente objetos. Los progresos, por su parte, no son divisibles sin negar a su vez tanto su naturaleza propia como duración, como la cualidad peculiar en la que se constituyen.

En otros términos, la divisibilidad de los pasos de Aquiles equivale a la negación de su naturaleza positiva, pues supone la negación del progreso simple y concreto que deja atrás a la tortuga y su lento caminar.

Con el fin de matizar la forma de la duración, Bergson señala que ésta se caracteriza por articularse justo en un impetu que no sólo es simple y creativo, sino también irrepetible. La duración no es repetible, en la medida que ésta no recorre un mapa predeterminado y ya recorrido, atendiendo a causas específicas que se articularan en una serie de leyes, sino que se constituye como siendo en su propia actividad. El presente de la duración nunca es idéntico a la forma de un pasado pretendidamente inmóvil, pues lo subsume para constituirse con él como la conquista permanente de un futuro siempre novedoso.

La duración se despliega en un impulso que dada su temporalidad peculiar y su carácter heterogéneo, supone una afirmación creativa que no podría repetirse al estar sujeta a una serie de causas externas que pudieran producir siempre los mismos efectos. La duración implica irrepetibilidad, ya que por naturaleza es singular, se resuelve en la producción de formas inéditas y nunca podría ser la misma que ha sido, sino sólo la que es en tanto lo que se hace. "Aquí la

${ }^{7}$ Ibid., p. 28. 
duración parece obrar justamente a la manera de una causa, y la idea de poner las cosas en su lugar al cabo de un cierto tiempo implica una especie de absurdo, ya que parecida vuelta atrás no se efectuó jamás en un ser viviente". ${ }^{8}$

La repetibilidad es una noción fundada en la categoría del espacio que sustituye a la duración como impulso creativo, por una representación que muestra una serie de detenciones sobre un plano que pueden ser recorridas indefinidamente, según la pauta de ciertas causas externas o transitivas.

La unidad móvil de la duración presenta una irrepetibilidad que le da a la cualidad en la que se manifiesta un carácter singular. En el dominio de la duración el presente atrae al pasado, lo proyecta al futuro y se determina como un proceso único y peculiar que no se tiene más que a sí mismo como forma y causa de la expresión creativa e inédita en la que se constituye como tal.

Así, apunta Bergson, la irrepetibilidad de la duración va acompañada de su imprevisibilidad, pues la propia forma móvil de ésta implica un impulso creativo que se constituye como tal sólo en la medida en que se actualiza a sí mismo, y no según una serie de causas primeras o finales que anticiparan el sentido de su desenvolvimiento.

La duración muestra una singularidad creativa que no podría preverse, pues su previsión supondría la detención del esfuerzo dinámico que la caracteriza, su división interna en una multiplicidad espacializada, y su reconstrucción con base en una causalidad externa, que señalara su futura determinación.

Sin duda, mi estado actual se explica por lo que había en mí y por lo que actuaba en mí hace un poco. No encontraría otros elementos en el análisis. Pero una inteligencia, incluso sobrehumana, no hubiese podido prever la forma simple, indivisible, que da a estos elementos completamente abstractos su organización concreta. Porque prever consiste en proyectar en el porvenir lo que se ha percibido en el pasado, o en representarse para más tarde una nueva ensambladura, en otro orden, de los elementos percibidos. Pero lo que no se ha percibido nunca y lo que es al mismo tiempo simple, resulta necesariamente imprevisible. Ahora bien, tal es el caso de cada uno de nuestros estados, considerado como un momento de una historia que se desarrolla: es simple, y no puede haber sido percibido ya, puesto que concentra en su indivisibilidad todo lo percibido junto con lo que, además, le añade al presente. Es un momento original de una no menos original historia. ${ }^{9}$

${ }^{8}$ Ibid., p. 101.

9 Ibid., "La evolución creadora", p. 499. 
La previsibilidad es un aspecto en el análisis de una duración que, al proyectarse sobre el espacio, se ha descompuesto en elementos homogéneos, divisibles y exteriores que implican la negación de su forma misma en tanto intensidad y unidad dinámica.

Desde la perspectiva de Bergson, la previsibilidad que presenta el conocimiento racional responde a la mediación que supone la categoría del espacio, en la cual se representan formas impenetrables que se relacionan bajo una causalidad transitiva en la que la realidad misma no aparece como duración o progreso inmanente, sino precisamente como multiplicidad cuantitativa.

Repetibilidad y previsibilidad ocultan el dato inmediato de una duración que se ofrece inmediatamente a la conciencia, formando parte del espectáculo meramente simbólico de una razón que se articula en la categoría del espacio homogéneo.

El conocimiento racional no es capaz de aprehender el progreso continuo en el que se articula la duración, ni la interpenetración móvil de la multiplicidad heterogénea que la constituye, es decir, aquellos intervalos que en tanto síntesis de dicha multiplicidad, resultan el horizonte donde ésta expresa su carácter dinámico y creativo.

La razón da lugar a la serie de esquemas que enarbolan la física y la matemática, y fracciona con ellos el movimiento continuo que caracteriza a la duración. Por ello, no aprehende cómo la cualidad misma en la que ésta se manifiesta no se puede reconstruir con una yuxtaposición de partes exteriores entre sí, pues dicha cualidad radica en los propios intervalos donde estas partes mismas se interpenetran y se articulan en una forma intensiva.

La razón no advierte que un adosamiento de inmovilidades no genera movilidad, ni una suma de simultaneidades una cualidad o un intervalo creativo, pues no reconoce tampoco que lo continuo no es producto de la suma de indefinidas repeticiones, ni que el tiempo es radicalmente diferente del espacio homogéneo.

La matemática, en tanto análisis de la categoría del espacio, hace de sus objetos simultaneidades impenetrables, de modo que no puede aprehender la forma de una realidad que se muestra directamente a la conciencia bajo la forma de un despliegue simple, heterogéneo e ininterrumpido que es causa de sí y que se resuelve en la promoción de formas singulares.

Pero la matemática rebasa este papel cuando pretende reconstruir lo que tiene lugar en el intervalo de dos simultaneidades; o al menos, es empujada fatalmente, incluso entonces, a considerar todavía simultaneidades, simultaneidades nuevas, cuyo número indefinidamente creciente debería advertirle que no se produce movimiento con inmovilidades, ni tiempo con espacio [...] Mas, precisamente por esta 
razón, la ciencia no opera sobre el tiempo y el movimiento sino a condición de eliminar primero de ellos el elemento esencial y cualitativo - del tiempo, la duración, y del movimiento, la movilidad. ${ }^{10}$

La duración en tanto despliegue continuo, resulta una forma de carácter cualitativo que no es reconstruible con base en una retahíla de inmovilidades adosadas. Esta serie de inmovilidades son producto de una espacialidad que no expresa el movimiento simple en la que la duración misma se articula, es decir, la penetración dinámica entre sus elementos o aquellos intervalos que constituyen su forma como un despliegue continuo y heterogéneo que se resuelve como ímpetu creativo.

En la duración toda supuesta detención participa inmediatamente de los intervalos de los que se destaca, de modo que la duración misma adquiere la forma de una multiplicidad cualitativa y no de una cantidad.

El conocimiento racional sólo toca lo inmóvil, no los intervalos por los cuales las simultaneidades mismas aparecen como momentos de un despliegue sostenido de cualidad que es tiempo y creación de formas inéditas.

Bergson es cuidadoso en poner énfasis en que el conocimiento racional no da lugar a un análisis de lo real que tuviera como preocupación su duración concreta y singular, sino que es el principio de una apreciación artificiosa de ésta que se apoya justamente en una serie de simultaneidades o inmovilidades impenetrables de las que sólo se puede derivar una concepción de carácter meramente esquemático. Para ello, concibe la hipótesis de una duplicación de la velocidad con la que transcurren los fenómenos astronómicos y lleva a cabo una serie de reflexiones respecto a la aprehensión inmediata que la conciencia pudiera tener de la misma.

Una duplicación de la velocidad con la que transcurren los fenómenos astronómicos no modificaría en absoluto la relación que éstos guardan entre sí, porque sus movimientos seguirían conservando las mismas proporciones con relación al conjunto y el orden mismo que constituyen. Sin embargo, apunta Bergson, la duplicación misma de la velocidad de dichos fenómenos modificaría profundamente la experiencia que el sujeto tendría de éstos, ya que la aceleración de los fenómenos en unidades menores de tiempo produciría otro tipo de interpenetración entre sus elementos constitutivos y por ello su expresión en formas e intervalos cualitativamente novedosos.

La duplicación de velocidad en el movimiento de los fenómenos astronómicos necesariamente generaría una modificación de carácter cualitativo que para la aprehensión inmediata de la conciencia sería innegable, pero que un puro análisis matemático resultaría incapaz de rastrear.

${ }^{10}$ Ibid., "Ensayo sobre los datos inmediatos de la conciencia", p. 76. 
Para hacer ver palpablemente esta diferencia capital, supongamos por un instante que un genio maligno, aún más poderoso que el genio maligno de Descartes, ordenase a todos los movimientos del universo que marchasen con doble velocidad. Nada se cambiaría en los fenómenos astronómicos o, al menos, en las ecuaciones que nos permiten preverlos, porque en estas ecuaciones el símbolo $t$ no designa una duración sino una relación entre dos duraciones, un cierto número de unidades de tiempo, o en fin, en último análisis, un cierto número de simultaneidades; estas simultaneidades, estas coincidencias se producirían todavía en número igual; únicamente habrán disminuido los intervalos que las separan, pero estos intervalos no entran para nada en los cálculos. Ahora bien, estos intervalos son precisamente la duración vivida, la que la conciencia percibe: también la conciencia nos advertiría aquí en seguida de una disminución de la jornada si, entre la salida y la puesta del sol, hubiésemos durado menos. No mediría sin duda esta disminución e incluso no la percibiría quizás al instante bajo el aspecto de un cambio de cantidad; pero comprobaría, bajo una u otra forma, un descenso en el enriquecimiento ordinario del ser, una modificación en el progreso que tiene costumbre de realizar entre la salida y la puesta del sol. ${ }^{11}$

La cualidad se constituye en el progreso y la concentración que presenta toda intensidad en tanto multiplicidad simple y heterogénea. Acelerar el movimiento mismo de la intensidad necesariamente cambiaría dicha cualidad, porque el despliegue y la interpenetración de los elementos que la conforman se modificarían dando lugar a la generación de formas totalmente inéditas. Bergson critica una razón que no toma en cuenta la naturaleza específica de una realidad que se determina como intensidad y por el contrario la reemplaza con una serie de elementos adosados. Estos elementos podrán sucederse con diferentes velocidades, pero no expresarán jamás la cualidad peculiar que caracteriza a la realidad misma en tanto duración y flujo creativo.

Para Bergson la razón no posee ningún instrumental teórico para dar cuenta del despliegue efectivo de lo real, pues la propia realidad, al aparecer como un despliegue intensivo, resulta inasible por la categoría del espacio en el que la razón misma funda sus concepciones.

Este autor rechaza la soberbia de todo conocimiento racional que pretenda dar cuenta de lo real, cuando la realidad misma se constituye en una duración que se resiste a caer en sus cuadros y a sufrir una reducción por la cual se desconozca su naturaleza creativa y su forma como despliegue inmanente.

${ }^{11}$ Ibid., p. 127. 
Ahora bien, la propia crítica bergsoniana al racionalismo filosófico da realce a la forma de la intuición como fundamento cabal del conocimiento metafísico. Desde la perspectiva de Bergson, la razón no constituye la vía adecuada para establecer una aprehensión de lo real que muestre su forma positiva, pues ésta se encuentra limitada por un formalismo que sólo reconoce formas estáticas. Es sólo la intuición la vía para dar cuenta de lo real, pues ésta se despliega en una simpatía que aprehende inmediatamente su forma en tanto duración y flujo creativo.

La razón como método de conocimiento resulta incapaz de asir una duración que se despliega como proceso simple e indivisible, y de manera independiente a toda espacialidad por la que se vea determinada como una serie de instantáneas exteriores entre sí que se yuxtaponen según cierta causalidad transitiva o final, o cierta movilidad mecanizada. La razón no puede atenazar la forma de la duración que se resuelve en la producción espontánea de formas novedosas, pues se detiene en la constante repetición de una serie de esquemas o símbolos sujetos a diversos patrones fundados en la categoría del espacio homogéneo.

Según Bergson, el conocimiento racional, en cualquiera de sus presentaciones históricas (platonismo, cartesianismo, kantismo, etcétera), no puede expresar la forma de lo real como duración, y más bien se atribuye arbitrariamente toda legitimidad en la determinación de los planos del ser y el conocer.

La intuición, en cambio, prescinde de todo concepto y todo símbolo para aprehender la forma de la duración, de modo que brinda un conocimiento directo de ésta que sustituye al juego dialéctico de la serie de perspectivas teóricas que se enquistan al interior de la propia representación: realismo, idealismo, criticismo, perspectivas éstas que sólo cambian el sistema de acentos en el emplazamiento de la categoría del espacio como horizonte constitutivo de los planos lógico y metafísico, pero que no aprehenden la propia forma de lo real como intensidad y unidad dinámica.

Para Bergson la intuición conoce directamente la forma de lo real, y por ello restituye a la metafísica un derecho y una objetividad que el solipsismo racional había terminado por entorpecer o anular. La intuición puede aprehender la forma creativa de la duración y por ello es capaz de traspasar los cuadros de la inteligencia acuñando conceptos o símbolos dúctiles y dinámicos que expresan su forma efectiva.

Los conceptos simples no tienen pues tan sólo el inconveniente de dividir la unidad concreta del objeto en otras tantas expresiones simbólicas; dividen también la filosofía en escuelas distintas, cada una de las cuales ocupa un lugar, escoge sus fichas y entabla con la otras una partida que no terminará jamás. O la metafísica no es más que este 
juego de ideas, o bien, si se trata de una ocupación seria del espíritu, es preciso que trascienda los conceptos para llegar a la intuición. Ciertamente, los conceptos le son indispensables, porque todas las demás ciencias trabajan ordinariamente sobre conceptos y la metafísica no podría prescindir de ellos. Pero la metafísica no es propiamente ella misma, más que cuando sobrepasa al concepto, o al menos cuando se libera de conceptos inflexibles y ya hechos para crear conceptos muy diferentes a los que manejamos habitualmente, quiero decir representaciones flexibles, móviles, casi fluidas, siempre prestas a moldearse sobre las formas fugaces de la intuición. Volveremos más adelante sobre este punto importante. Basta haber mostrado que nuestra duración puede sernos presentada directamente en una intuición, que puede sernos sugerida indirectamente por imágenes, pero que no podría -si damos a la palabra concepto su sentido propio- encerrarse en una representación conceptual. ${ }^{12}$

La intuición, para Bergson, a la vez que disloca los cuadros de la razón al asir inmediatamente la forma de una realidad que es duración, puede tomar sus conceptos, dinamizarlos y vivificarlos, otorgándole a la metafísica un horizonte expresivo para zanjar toda disputa epistemológico-ontológica derivada de la primacía de la categoría del espacio como soporte gnoseológico capital. La intuición es capaz de dar cuenta de lo real, pues crea símbolos plásticos que reflejan fielmente y comunican su forma sin atender a las exigencias lógicas propias de la representación.

La intuición no sólo burla las ilusiones cognoscitivas de una razón que no puede ir más allá de su dogmatismo y su solipsismo simbólico-esquemático, sino que se vale de las representaciones mismas que ésta ofrece o de una serie de imágenes determinadas para manifestar la forma de la duración que se constituye como intensidad o poder creativo.

Para Bergson, la intuición muestra directamente a la conciencia que lo real no presenta una estructura que se determina según los esquemas derivados de la categoría del espacio, sino que se constituye como una forma de intensidad que se realiza en su propia movilidad y sólo en ella. Lo real es duración, flujo, vibración que no puede verse reconstruida según una serie de formas estáticas que se recortan del espacio homogéneo.

Según Bergson, la intuición deja ver que lo real es una movilidad sin móvil, una movilidad sin fondo que recorrer, es decir, actividad que se resuelve en su propio despliegue y no un conjunto de formas inmóviles que cambiaran de posición según su cercanía a una serie de ideas trascendentes e idénticas a

${ }^{12}$ Ibid., "El pensamiento y lo moviente. Introducción a la metafísica", p. 1401. 
sí mismas (platonismo), según su lugar en un sistema de coordenadas espacio-temporales (cartesianismo) o según ciertas causas externas, ya sean primeras o finales.

Lo real es duración que reverbera aun en su aparente inmovilidad, pues es una intensidad creativa que sólo se tiene a sí misma como causa y no una forma estéril y estática que se hace posible únicamente al interior del propio cuadro de la representación.

Volvamos entonces la vista. Fijando más en ella nuestra atención, nos damos cuenta que el movimiento no exige aquí un vehículo, ni el cambio una sustancia, en el sentido corriente de la palabra. Ya la ciencia física nos sugiere esta visión de las cosas materiales. Cuanto más progresa, más resuelve la materia en acciones que caminan a través del espacio, en movimientos que corren aquí y allá como especie de escalofríos, de suerte que la movilidad se convierte en la realidad misma. Sin duda, la ciencia comienza por asignar a esta movilidad un soporte. Pero, a medida que avanza, el soporte retrocede; la masa se pulveriza en moléculas, las moléculas en átomos, los átomos en electrones o corpúsculos, finalmente, el soporte asignado al movimiento asemeja no ser más que un esquema cómodo, simple concesión del sabio a los hábitos de nuestra imaginación visual. Pero no hay necesidad de ir tan lejos. ¿Qué es el "móvil" al que nuestro ojo refiere el movimiento como a un vehículo? Simplemente una mancha coloreada, de la que sabemos perfectamente que se reduce, en sí misma, a una serie de oscilaciones extremadamente rápidas. Este pretendido movimiento de una cosa no es en realidad más que un movimiento de movimientos. ${ }^{13}$

La intuición sobrepasa el trabajo de la función de la razón y en esa medida puede asir una duración que se constituye como movilidad pura, como despliegue simple y autosuficiente, como un cambio sustancial. La movilidad o duración no se determina como atributo o accidente de una pretendida sustancia inmóvil, ni como consecuencia del cambio de referencias de un punto en relación con un plano estático, sino como una forma que desfonda los propios marcos de la razón y que tiene una realidad en sí.

Según Bergson la intuición revela la forma de lo real como flujo constante, como una intensidad que es en la medida que se hace, como poder de existir, acción, perseverar en el ser, actualización de una vida que se constituye en su propio despliegue creativo. La intuición vincula al sujeto a la forma de lo real, de modo que le permite aprehender su forma como una duración que no

${ }^{13}$ Ibid., "El pensamiento y lo moviente. La percepción del cambio", p. 1383. 
puede ser objetivada para ser negada justo en la actividad que resulta su forma esencial.

Para Bergson la intuición es el método de la filosofía, puesto que es capaz de aprehender de modo directo la forma de lo real como duración, sin caer en el juego de espejismos conceptuales que sostiene el conocimiento racional.

Como decíamos, según nuestro autor, la intuición puede abordar la forma de lo real sin negar su naturaleza en tanto intensidad creativa. La intuición capta la forma de una duración que se satisface en la producción de formas singulares. La intuición sigue de cerca la actualización de lo real, en términos de una duración que se despliega en la creación de formas impredecibles e irrepetibles.

El conocimiento racional, por el contrario, reduce toda duración y toda intensidad creativa a los esquemas inmóviles que se fundan en su propia estructura formal. La razón no puede asir el ímpetu creativo de la vida, pues, como hemos señalado, sólo puede concebir esquemas que encajan sobre esquemas, pero jamás un impulso simple que se constituye en su propia movilidad y que se despliega iluminando y trayendo al mundo formas novedosas.

La intuición simpatiza con la esencial movilidad de lo real, con una movilidad que es una duración que se rebasa constantemente a sí misma, dando a luz procesos inéditos, generando un despliegue constante que no podría ser rehecho con base en una serie de elementos inmóviles y exteriores entre sí. Para Bergson la intuición, a diferencia del conocimiento racional, puede conocer la forma de la realidad en sí, pues es capaz de pensar en duración.

Hay, sin embargo, un sentido fundamental: pensar intuitivamente es pensar en duración. La inteligencia parte ordinariamente de lo móvil y reconstruye, bien o mal, el movimiento con inmovilidades yuxtapuestas. La intuición parte del movimiento, lo pone, o, mejor, lo percibe como la realidad misma, y no ve en la inmovilidad más que un momento abstracto, instantáneo, tomado por nuestro espíritu sobre una movilidad. La inteligencia se da ordinariamente sobre las cosas, entendiendo por ello lo estable, $y$ hace del cambio un accidente que se sobreañade a ellas. Para la intuición lo esencial es el cambio: en cuanto a la cosa, tal como la entiende la inteligencia, es un corte practicado en medio del devenir y erigido por nuestro espíritu en sustituto del conjunto. El pensamiento se representa ordinariamente lo nuevo como un arreglo de elementos preexistentes; para él nada se pierde, nada se crea. La intuición, referida a una duración que es aumento, percibe ahí una continuidad ininterrumpida de imprevisible novedad. ${ }^{14}$

${ }^{14}$ Ibid., "El pensamiento y lo moviente. Del planteamiento de los problemas", p. 1275. 
La intuición es capaz de dar cuenta de la forma de una duración que se constituye como ímpetu creativo. Lo real es flujo creativo y la intuición, por un fenómeno de simpatía, puede asir su forma peculiar sin desvirtuarla por su sujeción a una serie de categorías a priori o conceptos preconcebidos. La intuición aprehende inmediatamente la movilidad y la creatividad sustancial de lo real y no la reduce a una retahíla de formas estáticas que en el fondo no son más que el producto de sendas representaciones articuladas en la categoría del espacio homogéneo.

Bergson hace una clara distinción entre el conocimiento racional y el conocimiento intuitivo, entre una representación fundada en la categoría del espacio y la aprehensión del tiempo o duración que se aparece inmediatamente a la conciencia. Esta distinción -que ayuda a horadar precisamente el solipsismo que constituye el conocimiento racional- muestra la forma de una realidad que es cambio, flujo, intensidad, creación. De este modo, Bergson procura un desplazamiento importante del horizonte en el que se fijan los problemas propios de la filosofía, estableciendo así los derroteros por los cuales transcurrirá su quehacer teórico: si el objeto de conocimiento metafísico por excelencia no es la Forma, la Ley, la Idea, en suma, el esquema-como rezan el platonismo más corriente, el cartesianismo, el kantismo o el hegelianismo, por ejemplo-, sino la duración, ¿qué rostro presentan problemas como el de la verdad, del bien, de la materia y de la forma misma del hombre y su libre albedrío? ¿Cómo pensar lo real y sus diversos dominios si no poseen una estructura estática pues se constituyen bajo la forma de la duración?

Bergson establece un ángulo de mirada por el que la determinación de la duración como objeto fundamental de la filosofía, a la vez que contraviene los hábitos y las inercias discursivas de una razón demasiado satisfecha con su propio formalismo, replantea los problemas y los objetos a los que se enfrenta la filosofía misma, justo a la luz de un enfoque cualitativo que la propia razón había terminado por anular. El análisis de los datos inmediatos de la conciencia procura un retorno a lo empírico que brinda un suspiro reflexivo a una filosofía que por el esquematismo de la razón había abandonado el ámbito de lo cualitativo y lo concreto. Así, la doctrina bergsoniana se presenta como un proyecto que a lo largo de su despliegue a través de $E l$ ensayo, Materia y memoria, La evolución creadora y Las dos fuentes de la moral y la religión, o sea, sus obras fundamentales, y más allá de sus resultados específicos (o quizá también justo por ellos), se presenta como un camino por andar, como una investigación sistemática, como una invitación a pensar.

Bergson mismo, a la vez que critica una razón que se resuelve como mera repetición solipsista, señala el propio planteamiento de los problemas como 
momento de una labor filosófica que hace el esfuerzo por seguir de cerca lo real.

Otro tanto sería decir que toda verdad es ya virtualmente conocida, que su modelo está depositado en los papeles administrativos de la ciudad y que la filosofía es un juego de puzzle en el que se trata de reconstruir, con algo que la sociedad nos suministra, el dibujo que no quiere mostrarnos. A lo mismo equivaldría asignar al filósofo el papel y la actitud del estudiante que busca la solución y pretende obtener con una mirada indiscreta, a la vista del enunciado, en el cuaderno del profesor. Pero la verdad es que se trata, tanto en filosofía como en cualquier otra parte, de encontrar el problema y por consiguiente de plantearlo, más todavía que resolverlo. Porque un problema especulativo queda resuelto desde el momento que está bien planteado. Entiendo por ello que existe solución, aunque pueda permanecer oculta y, por decirlo así, recubierta: falta sólo descubrirla. Pero plantear el problema no es simplemente descubrir, es inventar. ${ }^{15}$

Para Bergson la aprehensión de la forma de la duración aparece como criterio para reorientar el discurso filosófico, pues despeja el terreno para inquirir a lo real justo en tanto movilidad y proceso creativo, y no según la serie de concepciones que brinda una razón que no puede más que encadenar indefinidamente múltiples esquemas y de ningún modo dar cuenta de la duración misma que se aparece de manera inmediata a la conciencia: la conciencia misma, el cuerpo, la relación entre ambos, la evolución de las especies, la sociedad, la historia, etcétera, aparecen como problemas que se replantea la filosofía, en la medida que ésta se libera de los cuadros de la representación y aborda su propia forma intensiva.

Según nuestro autor, el conocimiento intuitivo es el método de la filosofía, en la medida que, una vez que se ha librado del esquematismo de la representación, aborda la forma efectiva de lo real como duración, y plantea y salva los problemas que orientan y estimulan el adecuado ejercicio de la filosofía misma. La intuición es para nuestro autor el detonante de una reflexión filosófica que al liberarse de los velos que la razón tiende sobre lo real y reconocer la forma de la duración, puede abordar la realidad misma como un problema que al ser salvado, puede hacer progresar de manera efectiva a la metafísica.

La filosofía bergsoniana, a través del despliegue doctrinal que va de $E l$ ensayo a Las dos fuentes, a la vez que lleva a cabo una crítica al racionalismo filosófico y a la ciencia moderna que destaca el resultado del ejercicio de la

15 Ibid., p. 1292. 
intuición como método de la filosofía, se satisface a sí misma como una máquina de interrogar y plantear problemas, como una máquina para desempolvar nuestra mirada sobre el mundo y arrojar al pensamiento a lo que más desea y a la vez más rehuye, que es su propio camino como pensar. 